\title{
VEGF-A and VEGF-B Coordinate the Arteriogenesis to Repair the Infarcted Heart with Vagus Nerve Stimulation
}

\author{
Yan-xia LV ${ }^{a, b}$ Sen Zhong ${ }^{a, c} \quad$ Hexin Tang ${ }^{a, b}$ Bin Luo ${ }^{a, b} \quad$ Shao-Juan Chen ${ }^{a, d}$ \\ Long Chen ${ }^{a, b}$ Fei Zheng ${ }^{a}$ Lei Zhang ${ }^{a} \quad$ Lu Wang $^{a}$ Xing-yuan Li ${ }^{a} \quad$ Yu-wen Yan ${ }^{a}$ \\ Ya-mu Pan ${ }^{a}$ Miao Jiang ${ }^{\text {a }}$ You-en Zhang ${ }^{a}$ Lei Wang ${ }^{a}$ Jian-ye Yang ${ }^{a}$ \\ Ling-yun Guo ${ }^{a}$ Shi-you Chen ${ }^{f}$ Jia-ning Wang ${ }^{a, e} \quad$ Jun-ming Tanga,be
}

Institute of Clinical Medicine and Department of Cardiology, Renmin Hospital, Hubei University of Medicine, Shiyan, Hubei, b Department of Physiology, School of Basic Medicine Science, Hubei University of Medicine, Hubei, 'Department of Paediatrics, Renmin Hospital, Hubei University of Medicine, Shiyan, Hubei, dDepartment of Stomatology, Taihe Hospital, Hubei University of Medicine, Shiyan, Hubei, eHubei Key Lab of Embryonic Stem Cell and Institute of Biomedicine, Hubei University of Medicine, Hubei, China, fDepartment of Physiology \& Pharmacology, The University of Georgia, Athens, GA, U.S.A.

\section{Key Words}

Myocardial infarction • Vagal nerve stimulation • Angiogenesis • VEGF-A • VEGF-B

\begin{abstract}
Background/Aims: Vagus nerve stimulation (VNS) suppresses arrhythmic activity and minimizes cardiomyocyte injury. However, how VNS affects angiogenesis/arteriogenesis in infarcted hearts, is poorly understood. Methods: Myocardial infarction (MI) was achieved by ligation of the left anterior descending coronary artery $(L A D)$ in rats. 7 days after LAD, stainlesssteel wires were looped around the left and right vagal nerve in the neck for vagus nerve stimulation (VNS). The vagal nerve was stimulated with regular pulses of $0.2 \mathrm{~ms}$ duration at 20 $\mathrm{Hz}$ for 10 seconds every minute for 4 hours, and then ACh levels by ELISA in cardiac tissue and serum were evaluated for its release after VNS. Three and 14 days after VNS, Real-time PCR, immunostaining and western blot were respectively used to determine VEGF-A/B expressions and $\alpha$-SMA- and CD31-postive vessels in VNS-hearts with pretreatment of $\alpha 7$-nAChR blocker mecamylamine (10 mg/kg, ip) or mACh-R blocker atropine (10 mg/kg, ip) for 1 hour. The coronary function and left ventricular performance were analyzed by Langendorff system and hemodynamic parameters in VNS-hearts with pretreatment of VEGF-A/B-knockdown or VEGFR blocker AMG706. Coronary arterial endothelial cells proliferation, migration and tube formation were evaluated for angiogenesis following the stimulation of VNS in coronary arterial smooth muscle cells (VSMCs). Results: VNS has been shown to stimulate VEGF-A and VEGF-B expressions in coronary arterial smooth muscle cells (VSMCs) and endothelial cells
\end{abstract} Yan-xia Lv and Sen Zhong contributed equally to this work. 
(ECS) with an increase of $\alpha$-SMA- and CD31-postive vessel number in infarcted hearts. The VNS-induced VEGF-A/B expressions and angiogenesis were abolished by $m$-AChR inhibitor atropine and $\alpha 7-n A C h R$ blocker mecamylamine in vivo. Interestingly, knockdown of VEGF-A by shRNA mainly reduced VNS-mediated formation of $\mathrm{CD} 1^{+}$microvessels. In contrast, knockdown of VEGF-B powerfully abrogated VNS-induced formation of $\alpha$-SMA ${ }^{+}$vessels. Consistently, VNS-induced VEGF-A showed a greater effect on EC tube formation as compared to VNS-induced VEGF-B. Moreover, VEGF-A promoted EC proliferation and VSMC migration while VEGF-B induced VSMC proliferation and EC migration in vitro. Mechanistically, vagal neurotransmitter acetylcholine stimulated VEGF-A/B expressions through m/nACh-R/PI3K/ $A k t / S p 1$ pathway in EC. Functionally, VNS improved the coronary function and left ventricular performance. However, blockade of VEGF receptor by antagonist AMG706 or knockdown of VEGF-A or VEGF-B by shRNA significantly diminished the beneficial effects of VNS on ventricular performance. Conclusion: VNS promoted angiogenesis/ arteriogenesis to repair the infracted heart through the synergistic effects of VEGF-A and VEGF-B.

\section{Introduction}

Myocardial infarction (MI) damages cardiac function, leading to heart failure (HF) accompanied by an autonomic imbalance characterized by both increased sympathetic activity and decreased vagal activity [1]. Vagal nerve stimulation (VNS), a novel therapeutic strategy for autonomic dysfunction, has been shown to activate cholinergic anti-inflammatory pathways to improve cardiac function and long-term survival in MI patients and MI animal models besides its anti-adrenergic and anti-arrhythmic activities [2-5]. However, whether or not VNS affects angiogenesis/arteriogenesis during the heart repair remains to be determined.

Angiogenesis (i.e. Growth of new blood vessels from preexisting ones) and arteriogenesis (i.e. the formation of collateral arteries from preexisting arterioles) are essential for reestablishing blood supply to the surviving myocardium and the recovery of ventricular function after MI [6]. The autonomic imbalance after MI impairs the angiogenesis in infarcted heart due to the decreased expressions of the $\alpha 7$-nicotinic acetylcholine (ACh) receptors ( $\alpha 7$ $\mathrm{nAChR}$ ) in MI-heart [7, 8]. Indeed, vagal innervation of the conduction system and coronary vessels in heart [9] and the increased ACh concentration in left ventricular and circulation are observed when exposed to VNS [2, 10-13]. Since VNS mainly promotes $\alpha 7$-nAChR and m3-AChR expression in ischemia-reperfusion heart [14], activation of either $\alpha 7$-nAChR or m3-AChR by ACh may mediate VNS-induced angiogenesis in infarcted heart. However, little is known about if and how VNS can promote angiogenesis and arteriogenesis.

Different member of the vascular endothelial growth factor (VEGF) family appears to have a specific function: VEGF-A induces angiogenesis in the heart, especially during hypoxia and nutrient deprivation $[15,16]$. VEGF-B and VEGF-E mediates both angiogenesis and arteriogenesis $[17,18]$, while VEGF-C and VEGF-D act mainly as lymphangiogenic factors [19]. Activation of $\alpha 7-n A C h R$ by nicotine has been shown to induce the expressions and releases of VEGF-A in endothelial cells (EC), triggering endothelial cell-mediated angiogenesis [7]. However, VEGF-A gene therapy does not lead to an increased angiogenesis or improved heart function [20], indicating that other factors may also be required for VNS-induced angiogenesis. In the present study, we found that mainly VEGF-A and VEGF-B were induced in vascular smooth muscle cells (VSMCs) and ECs of coronary arteries along with increased angiogenesis and arteriogenesis after VNS. We thus hypothesized that VNS promoted angiogenesis and arteriogenesis in the injured heart through inducing both VEGF-A and VEGF-B. 


\section{Cellular Physiology Cell Physiol Biochem 2018;48:433-449 and Biochemistry Published online: July 17, $2018 \quad \begin{aligned} & \text { DOI: 10.1159/000491775 } 2018 \text { The Author(s). Published by S. Karger AG, Basel } \\ & \text { www.karger.com/cpb }\end{aligned}$}

Lv et al.: VNS Arteriogenesis VEGF-A/B Infarcted Heart

\section{Materials and Methods}

\section{Animals}

Animal studies are performed by strictly following the Guide for the Care and Use of Laboratory Animals published by the US National Institutes of Health. Adult male Sprague-Dawley rats (250-300 g) were purchased from the Experimental Animal Centre of Hubei University of Medicine, and all animal protocols were approved by the Institutional Animal Care and Use Committee of Hubei University of Medicine.

\section{Model establishment}

MI was achieved by ligation of the left anterior descending coronary artery (LAD) as previously described [20]. Briefly, SD rats (250-300 g) were anesthetized with ketamine (50 mg/kg, i.p.) and xylazine (10 mg/kg, i.p.). Tracheal ventilation with room air was carried out by using a Colombus ventilator (HX300, Taimeng Instruments, Chengdu, China). Following left lateral thoracotomy at the fourth intercostal space, the LAD was ligated. Before chest closure, infarction was confirmed by observation of the injury demarcation with blanching of the myocardium as well as electrocardiography.

\section{Vagus nerve stimulation}

A pair of Teflon-coated stainless-steel wires (UL1330; Triumph Cable Co, Ltd, Tonguing, China) was looped around the left and right vagal nerve in the neck for electrical stimulation. The wires were connected to the output terminals of the stimulator (BL-420S Data Acquisition \& Analysis System; Chengdu Tme Technology Co, Ltd.), which provide stimulation over a range of frequencies (0.1-100 Hz), strengths (1-10 $\mathrm{V}$ ) and pulse widths (0.001-10 sec). 7 days after the LAD ligation, survivors were randomized into groups with sham or active stimulation. In the actively stimulated group (VNS), the vagal nerve was stimulated with regular pulses of $0.2 \mathrm{~ms}$ duration at $20 \mathrm{~Hz}$ for 10 seconds every minute for 4 hours [2, 5]. In the sham group (MI), similar procedures were executed without initiating the vagal nerve stimulation. The electrical voltage of pulses was optimized in each rat to obtain a $10 \%$ reduction in heart rate. To prevent drying and to provide insulation, the electrodes and the vagus nerve were immersed in a mixture of white petrolatum (Vaseline) and paraffin.

\section{ELISA for ACh detection}

To detect ACh levels in cardiac tissue and serum $4 \mathrm{~h}$ after VNS, heart tissues and blood samples from six rats per group were collected and processed with cholinesterase inhibitor eserine (100 uM) added. ELISA for ACh was performed using a commercial kit by following the manufacture's protocol (ab65345, Abcam).

\section{Ach receptor inhibitor treatment in vivo}

The role of mACh-R and $\alpha 7-n A C h R$ in VNS-induced VEGF expressions in the infracted heart was assesses by administration of mecamylamine (10 mg/kg, ip) or atropine (10 mg/kg, ip) into six animals/ group $1 \mathrm{~h}$ before VNS, as described previously [14].

\section{Administration of VEGF-R inhibitor in vivo}

The role of VEGF-R in VNS-induced angiogenesis in the infracted heart was evaluated by the oral administrations of VEGF-R inhibitor AMG 706 (3 mg/kg, MedChemExpress) or vehicle $\left(\mathrm{H}_{2} \mathrm{O}\right)$ for 7 days at the end of VNS (6 rats/ group), as described previously [21].

\section{Construction of VEGF short hairpin RNA (shRNA) adenoviral vector}

VEGF-A165 shRNA (shVEGF) were designed using a dedicated program provided by OriGene. Oligonucleotides corresponding to the nucleotides in rat and human VEGF-A165 and VEGF-B mRNA were synthesized by Sangon Biotech (Shanghai). The shRNA sequences were: VEGF-A165: GAGTTAAACGAACGTACTTGCAGATGTGA; VEGF-B for rat: AGATGCACAAATCAGATGGTG; VEGF-B for human: AAUUUCCUGUCACGACACUUCGGUCUG. The Double-stranded DNA fragment was cloned into the MluI/ HindIII restriction site of the pRNAT-H1.1/Adeno vector (GenScript Corporation., America), resulting in pRNAT-H1.1-shVEGF165. The inserted sequences were verified by restricted enzyme digestion and DNA sequencing. Adenovirus expressing shVEGF-A or shVEGF-B was packaged in BJ5183-AD-1 (Agilent) and propagated in AD-293 cells (Invitrogen) by following the manufacture's instruction. The adenovirus was purified by cesium chloride density gradient centrifugation $[3,4]$. 


\section{Cellular Physiology and Biochemistry \\ Cell Physiol Biochem 2018;48:433-449 \\ DOI: $10.1159 / 000491775$ \\ Published online: July 17, 2018 \\ C) 2018 The Author(s)
www.karger.com/cpb}

Lv et al.: VNS Arteriogenesis VEGF-A/B Infarcted Heart

\section{Knockdown of VEGF-A/B in vivo}

To determine the effect of VEGF-A or VEGF-B on angiogenesis in the infracted heart, Ad-shCtrl, AdshVEGF-A, or Ad-shVEGF-B $\left(1 \times 10^{9} \mathrm{pfu}\right.$ in $\left.200 \mu \mathrm{l}\right)$ were injected into four sites of the infarcted hearts $(50 \mu \mathrm{l}$ per site, 12 rats/group) with a 30-gauge tuberculin syringe 3 day before the VNS. Two injections were in the myocardium bordering the ischemic area and two within the ischemic area [20]. Penicillin (150, $000 \mathrm{U} / \mathrm{mL}$, i.v.) was given before each procedure. Buprenorphine hydrochloride $(0.05 \mathrm{mg} / \mathrm{kg}$, s.c.) was administered twice a day for the first 48 hours after the procedure.

\section{Measurement of hemodynamic parameters}

Hemodynamic parameters were measured 28 days after each treatment as described previously [22]. Rats were anesthetized with ketamine $(50 \mathrm{mg} / \mathrm{kg}$, i.p.) and xylazine $(10 \mathrm{mg} / \mathrm{kg}$, i.p.). The left carotid artery was isolated. A catheter filled with heparinized $(10 \mathrm{U} / \mathrm{mL})$ saline solution and connected to a Statham pressure transducer (Gould, Saddle Brook, NJ, USA) was inserted into the carotid artery and advanced into the left ventricle to record ventricular pressure. Hemodynamic parameters including left ventricular systolic pressure (LVSP), left ventricular end-diastolic pressure (LVEDP), and rate of rise and fall of ventricular pressure $\left(+\mathrm{dP} / \mathrm{dt}_{\max }\right.$ and $-\mathrm{dP} / \mathrm{dt}_{\max }$ ) were measured simultaneously using BL-420s (Chengdu Tai-meng, Co, China). The heart was rapidly removed for other analyses after the measurements.

\section{Coronary flow Assay}

Six SD rats (250-300 g)/group were anesthetized with ketamine (50 mg/kg, i.p.) and xylazine (10 $\mathrm{mg} / \mathrm{kg}$, i.p.). A thoracotomy was performed, and hearts rapidly excised into ice-cold perfusion fluid. The aorta was cannulated on a shortened and blunted 14-gauge needle, and perfusion initiated at a constant pressure of $80 \mathrm{mmHg}$ on the Langendorff system. A fluid-filled balloon constructed from polyvinyl chloride film was introduced into the left ventricle through an incision in the left atrial appendage. Two tubes were introduced into the right atrial appendage through superior and inferior caval vein. Hearts were immersed in warmed perfusate in a jacketed bath maintained at $37^{\circ} \mathrm{C}$, and perfusate delivered to the coronary circulation was maintained at the same temperature using a super constant temperature water bath. Organ bath and perfusate temperatures were continuously monitored using digital thermometer. Langendorff-perfused hearts were allowed to equilibrate until heart rate and contractility reached steady state for $30 \mathrm{~min}$. Total coronary flow within $30 \mathrm{~min}$ was collected in the cylinder through tubes linked to right atrial appendage for evaluating coronary flow percentage/min. The Krebs-Henseleit perfusion fluid (containing NaCl, $119 \mathrm{mM}$; glucose, $11 \mathrm{mM}$; $\mathrm{NaHCO}_{3}, 22 \mathrm{mM}$; KCl, $4.7 \mathrm{mM}$; $\mathrm{MgCl}_{2}, 1.2 \mathrm{mM} ; \mathrm{KH}_{2} \mathrm{PO}_{4^{\prime}}, 1.2 \mathrm{mM} ; \mathrm{CaCl}_{2}, 2.5 \mathrm{mM}$; EDTA, $0.5 \mathrm{mM}$; and pyruvate, $2 \mathrm{mM}$ ) was used in all experiments. The fluid with a $\mathrm{pH}$ of 7.4 was bubbled with a mixture of $95 \% \mathrm{O}_{2}$ and $5 \% \mathrm{CO}_{2}$ at $37^{\circ} \mathrm{C}$ and was filtered through $0.45 \mu \mathrm{m}$ filter before delivery to the heart [23].

\section{Cell cultures and groups}

Human coronary microvessel endothelial cells (HCMECs), human vascular smooth muscle cells (HVSMCs) and human coronary artery endothelial cells (HCAECs) were purchased from the Jennio Biotech Co. Ltd (GuangZhou, China). To observe the effects of the different cells derived conditioned medium (CM) on HCAECs tube formation, CM from HVSMCs or HCAECs were generated as follows: for purpose of normalization, $3 \times 10^{6}$ HCAECs or HVSMCs were cultured in $100 \mathrm{~mm}^{2}$ dish for $24 \mathrm{~h}$ in a complete medium. And then the cells were cultured for $24 \mathrm{~h}$ in new complete medium with (CM-ACh) or without (CM-Ctrl) $10^{-}$ ${ }^{5} \mathrm{M}$ ACh at $37{ }^{\circ} \mathrm{C}$ with $5 \%$ of $\mathrm{CO}_{2}$. The corresponding $\mathrm{CM}$ were collected and centrifuged to remove the cells for subsequent experiments. For HCAECs tube formation assay, these specific CM from either HCAECs or HVSMCs were divided into ${ }^{\text {HvsMCs }} \mathrm{CM}$-Ctrl, ${ }^{\text {HvsMCs }} \mathrm{CM}$-ACh, and ${ }^{\text {HvSMCs }} \mathrm{CM}$-ACh+AMG706 (VEGFR inhibitor, $2 \mathrm{nM}$ ); ${ }^{\text {HCAECSC}} \mathrm{CM}-\mathrm{Ctrl}$, ${ }^{\text {HCAECS }} \mathrm{CM}-\mathrm{ACh}$, and ${ }^{\text {HCAECS }} \mathrm{CM}-\mathrm{ACh}+\mathrm{AMG} 706$, respectively.

To further confirm if VEGF-A or VEGF-B in CM was involved in HCAECs tube formation, the following CM from HVSMCs or HCAECs was generated as follows: $3 \times 10^{6}$ HVSMCs or HCAECs were cultured in 100 $\mathrm{mm}^{2}$ dish for $24 \mathrm{~h}$ in a complete medium. And then the cells were transfected with Ad-GFP, Ad-shVEGF-A or Ad-shVEGF-B for $24 \mathrm{~h}$. Subsequently, the cells were cultured for $24 \mathrm{~h}$ in new complete medium with (CMGFP-ACh, CM-shVEGF-A and CM-shVEGF-B) or without (CM-GFP) $10^{-5} \mathrm{M}$ ACh at $37{ }^{\circ} \mathrm{C}$ with $5 \%$ of $\mathrm{CO}_{2}$. For HCAECs tube formation assay, these specific CM from either HCAECs or HVSMCs were divided into ${ }^{\mathrm{HvSMCS}} \mathrm{CM}$ -

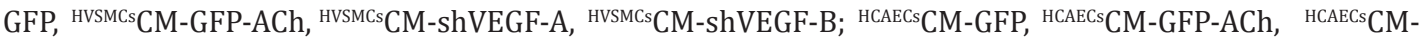

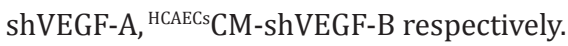




\section{Cellular Physiology Cell Physiol Biochem 2018;48:433-449 \begin{tabular}{c|c|c|c|} 
DOI: 10.1159/000491775 & $\begin{array}{l}\text { O } 2018 \text { The Author(s). Published by S. Karger AG, Basel } \\
\text { www.karger.com/cpb }\end{array}$
\end{tabular}}

Lv et al.: VNS Arteriogenesis VEGF-A/B Infarcted Heart

To further addressed the possible signaling mechanism of the ACh-induced VEGF-A/B expressions in HVSMCs, mACh-R inhibitor atropine $(1 \mu \mathrm{M})$ or nACh-R inhibitor mecamylamine $(7 \mu \mathrm{M})$, PI3K/Akt inhibitors Wortmannin $(50 \mathrm{nM})$ and LY294002 $(10 \mu \mathrm{M})$, eNOS inhibitor L-NAME $(300 \mu \mathrm{M}), \mathrm{MEK} /$ ERK1/2 inhibitor PD98059 $(50 \mu \mathrm{M})$, p38MAPK inhibitor SB203580 $(30 \mu \mathrm{M})$ or Sp1 inhibitor mithramycin $(1 \mu \mathrm{M}$, Sp1-I) were respectively pretreated for 1 hour, then treated with $\mathrm{ACh}\left(10^{-5} \mathrm{M}\right)$ for 24 hours. These cells were harvested and lysed in RAPI buffer with protease and phosphatase inhibitors for western blot.

\section{EC tube formation assay}

The corresponding CM were collected and centrifuged to remove the cells. EC tube formation was performed as described [24]. Briefly, HCAECs $\left(4 \times 10^{5} / \mathrm{ml}\right)$ were seeded in 96-well plates coated with Matrigel $^{\mathrm{TM}}$ and incubated in the CM collected. Where indicated, $2 \mathrm{nM}$ of AMG706 was added 30 minutes prior to changing to CM. For this assay, 3 duplicated wells/group were used, and the total number of tube branches (in pixels) per well was quantified using the Image-Pro Plus software package (Media Cybernetics, Carlsbad, CA) and averaged. The cells were then incubated at $37^{\circ} \mathrm{C}$ with $5 \%$ of $\mathrm{CO}_{2}$ for $6 \mathrm{~h}$, fixed in formalin, washed with PBS, imaged using microscopy. All measurements were repeated for 3 times and performed by two independent examiners who were blinded from the experimental groups.

For this assay, 3-4 wells/treated were performed, and the total number of tubes per well was quantified and averaged. Cells were incubated at $37^{\circ} \mathrm{C}$ for $16 \mathrm{~h}$, fixed in formalin, washed with PBS, and imaged using microscopy. Number of tube branches (in pixels) was quantified using ImageJ software (NIH).

\section{Cell Counting Kit-8}

HVSMCs or HCAECs $\left(2 \times 10^{4}\right.$ cells/well) were seeded in 96-well plates and incubated for $24 \mathrm{~h}$ at $37^{\circ} \mathrm{C}$ followed by stimulation with growth factors. Thereafter, $10 \mu \mathrm{L}$ of CCK-8 solution (Dojindo) was added to each well and incubated for 4 . The samples were then detected at $450 \mathrm{~nm}$ by a microplate reader (Bio-Rad, Hercules, CA, USA), and analyzed using the mathematical formula [(OD value of test - OD value of blank)/ (OD value of control - OD value of blank)] to quantify the cell viability. In each group, three replicates were executed, and three or five independent experiments were implemented [25].

\section{Wound healing assay}

HVSMCs or HCAECs were plated on a 6-well plate overnight with 10\% FBS-containing DMEM and then starved for $12 \mathrm{~h}$ for synchronization. Each well was scratch-wounded with a micropipette tip and washed twice with PBS to remove the floating cells. The cells were then cultured in serum-free medium containing different dosage of VEGF-A or VEGF-B, and then digital images of the scratch-wound area were acquired at $0,4,8 \mathrm{~h}$ after wounding following dying with Crystal Violet Staining Solution. The gap areas relative to those measured at $0 \mathrm{~h}$ after wounding were quantified [25].

\section{Western blot}

Western blot was carried out with rabbit polyclonal antibody against VEGF-B (1:1000; Abcam), Sp1, (1:1000; Santa Cruz), rabbit-anti-rat VEGF-A (1:1000; Abcam), p-Sp1 (1:1000; Abcam), Akt and pAkt (1:1000; Cell Signaling). Rat left ventricles were removed and grinded in liquid nitrogen. The samples were collected and homogenized on ice in a $0.1 \%$ Tween- 20 homogenization buffer containing protease inhibitors. $50 \mu \mathrm{g}$ of proteins were resolved in 10\% SDS-PAGE gel and transferred onto a polyvinylidene fluoride (PVDF) membrane (Millipore). After being blocked with 5\% nonfat milk, the membrane was incubated with primary antibody (1:1000 dilution) for 90 min followed by incubation with horseradish peroxidase (HRP)-conjugated secondary antibodies (anti-rabbit IgG, anti-mouse IgG, 1:10000, Jackson ImmunoResearch). Protein expression was visualized by enhanced chemiluminescence reaction (Amersham Pharmacia Biotech) and quantified by densitometry [20].

\section{Immunostaining}

Heart tissues were immersion-fixed in $4 \%$ paraformaldehyde and embedded in paraffin. Serial transverse sections $(5 \mu \mathrm{m})$ were cut across the entire long axis of the heart and mounted on slides. After dewaxing, hydration and heat-induced antigen retrieval, heart specimens were incubated in a blocking buffer (PBS containing 5\% goat serum and 0.1\%Triton X-100) at room temperature for $1 \mathrm{~h}$. Incubations in antibodies (diluted 1:250 in blocking buffer) were carried out at $4^{\circ} \mathrm{C}$ overnight for primary antibodies, 
Lv et al.: VNS Arteriogenesis VEGF-A/B Infarcted Heart

and room temperature for $2 \mathrm{~h}$ for secondary antibodies. The primary antibodies used were: mouse antirat a-SMA (sc-130616; 1:100, Santa Cruz), rabbit anti-rat VAChT (No.139 103; 1:250; Synaptic Systems); rabbit anti-rat CD31 (1:250; Abcam), rabbit-anti-rat VEGF-B (ab185696; 1:200; Abcam) and rabbit-anti-rat VEGF-A (ab46154; 1:200; Abcam). The secondary antibodies were horseradish peroxidase (HRP)-labeled goat anti-mouse IgG, goat-anti-rabbit IgG, FITC-conjugated anti-rabbit IgG, or TRITC-conjugated anti-mouse IgG (Jackson ImmunoResearch), respectively [20, 26].

\section{Measurement of vascular density}

The effect of VNS on vascular density was determined by quantifying the number of CD31 or a-SMA positive vessels per squared millimeter in both the peri-infarction and infarction area in six animals each group. Measurements were performed on three equidistant sections between the apex and ligature (at the midpoint between the LAD ligature and the apex, between the midpoint and the LAD ligature, and between the midpoint and the apex). In each section, the number of CD31 or a-SMA-positive vessels in eight equally distributed areas of $0.1 \mathrm{~mm}^{2}$ in the infarction area and six equally distributed areas of $0.1 \mathrm{~mm}^{2}$ in both peri-infarction areas were counted in blind fashion at a $20 \times$ magnification. The values were then expressed as the number of vessels per squared millimeter. All measurements were performed by two independent examiners who were blinded from the experimental groups using the Image-Pro Plus software package (Media Cybernetics, Carlsbad, CA) [27].

Quantitative reverse transcription polymerase chain reaction ( $q P C R$ )

Total RNA from the tissues or cultured HVSMCs was extracted using TRIZOL Reagent (Roche). qPCR was performed using FastStart Universal SYBR Green Master (Roche). The primer sequences were listed in Table 1. qPCR was performed on a Real-time PCR Detection System (ABI-7000).

\section{Statistical analyses}

Data shown are mean \pm SD. Statistical significance between two groups was determined by paired or unpaired Student's $t$-test. Results for more than two experimental groups were evaluated by one-way ANOVA to specify differences between groups. $P<0.05$ was considered significant.

\section{Results}

\section{Cardiac vagal innervation and ACh releases in infarcted hearts}

The cardiac vagal innervation in the large and small coronary arteries was shown by double immunostaining of a-SMA and VACHT (Fig. 1A). Along with the VNS, there was an increase in ACh levels in heart tissues and serum (Fig.1B), indicating that VNS caused cardiac vagus nerve to release more ACh.

\section{VNS increased coronary blood flow}

As the vagal neurotransmitter, ACh regulates coronary EC function and coronary blood flow $[28,29]$. We used langendroff perfused heart system to evaluate coronary microvascular function ex vivo and found that VNS increased coronary blood flow of the infarcted hearts (Fig. 1C), along with improved heart function (Fig. 1D-1G). However, these beneficial effects were abolished by either atropine $(10 \mathrm{mg} / \mathrm{kg}$, ip) or mecamylamine (10 $\mathrm{mg} / \mathrm{kg}$, ip) (Fig. 1), indicating

Table 1. The sequences of primer for qPCR

\begin{tabular}{|c|c|c|c|}
\hline Name & Forward & Reverse & Size(bp) \\
\hline VEGF-A & 5'-CCCTGGCTTTACTGCTGTAC-3' & 5'-TCTGAACAAGGCTCACAGTG-3' & 360 \\
\hline VEGF-B & 5'-AAGCTCTATGACAGGGACAACG-3' & 5'-CACTATGGAACAGAGAAGGGCTAC-3' & 185 \\
\hline VEGF-C & 5'CGCT GTGTCCCATCATATTG -3' & 5'-CCATGGTCCCACAGAGTCTT-3' & 138 \\
\hline VEGF-D & 5'-CGTGGGGGAGTCCTTGACTA-3' & 5'-TCGCTCAAGAGAAACATCCTTCA-3' & 297 \\
\hline VEGF-E & 5'-CTCCTCCTGCTGACATCTGC-3' & 5'-AAATGTCAGCTGGATCCGCA-3' & 255 \\
\hline PIGF & 5'-CAGCCAACATCACTATGCAG-3' & 5'-TCCTCTGAGTGGCTGGTTA-3' & 229 \\
\hline Flt1 & 5'-ATGGCATCCCTCAGCCTACC-3' & 5'-CACCACCAATGTGCTAACCG-3' & 203 \\
\hline Flk1 & 5'-AGCTCAGGTTTTGTGGAGGA-3' & 5'-CCAAGAACTCCATGCCCTTA-3' & 139 \\
\hline M3-AChR & 5'-TGCCTGGGTCTCTTAATTCC-3' & 5'-CTTCACATGGGATCTGGATG-3' & 114 \\
\hline$\alpha 7-\mathrm{nACh}-\mathrm{R}$ & 5'-AGATGGCCAGATTTGGAAACC-3' & 5'-GCAGGAACTCTTGAATATGCCT-3' & 229 \\
\hline$\beta$-actin & 5'-TGGGTATGGAATCCTGTGGCA -3' & 5'-TGTTGGCATAGAGGTCTTTACGG-3' & 90 \\
\hline
\end{tabular}




\section{Cellular Physiology Cell Physiol Biochem 2018;48:433-449 \begin{tabular}{c|c} 
DOI: 10.1159/000491775 & $\begin{array}{l}\text { O 2018 The Author(s). Published by S. Karger AG, Basel } \\
\text { www.karger.com/cpb }\end{array}$
\end{tabular} Lv et al.: VNS Arteriogenesis VEGF-A/B Infarcted Heart}

that VNS improved coronary microvascular function through m-ACh-R and $\alpha 7-n A C h-R$.

VNS induced angiogenesis and arteriogenesis through $\mathrm{m} / \mathrm{n}$ ACh-R

Recent studies showed that angiogenesis and arteriogenesis contribute to the improvement of coronary function [30]. In order to evaluate VNS effect on angiogenesis and arteriogenesis, CD31 (a mature endothelial cell marker) and $\alpha$-SMA (a vascular smooth muscle cells marker) were used to quantify the number of capillary and artery vessels. As shown in Fig. $2 \mathrm{~A}$, the numbers of CD31- and $\alpha$-SMApositive vessels were increased in VNS-treated hearts. The phenomena were abolished by either mACh-R inhibitor atropine $(10 \mathrm{mg} / \mathrm{kg}$, ip) or $\alpha 7-n A C h-R$ blocker mecamylamine (10 $\mathrm{mg} / \mathrm{kg}$, ip). Interestingly, mecamylamine showed a greater inhibition on VNS-induced formation of $\alpha$-SMA-positive vessels VNS than atropine. These results together with the data shown in Fig. 1 supported the concept that both VNS-induced angiogenesis and arteriogenesis were critical for the improved coronary function.

VNS-induced VEGF expressions through $m / n-A C h-R$

Since VEGF family proteins play critical role in controlling angiogenesis [31], we sought to determine if any member of the VEGF family is involved in VNSmediated angiogenesis. Thus, we examined the expression of VEGF-A, VEGF-B, VEGF-C, VEGF-D and VEGF-E by real-time PCR and found that only VEGF-A and VEGF-B expression were markedly increased in the VNS-treated hearts (Fig. 3A). Consistently, both VEGF receptors Flt1 and Flk1 were also increased in VNS-hearts as compared to the MI-hearts (Fig. 3B). Immunostaining showed that VEGF-A and VEGF-B were induced mainly in ECs and VSMCs of small and large coronary vessels in infarction (Fig. 3C-3F) and peri-infarction (Fig. 4A) areas of the infarcted hearts.

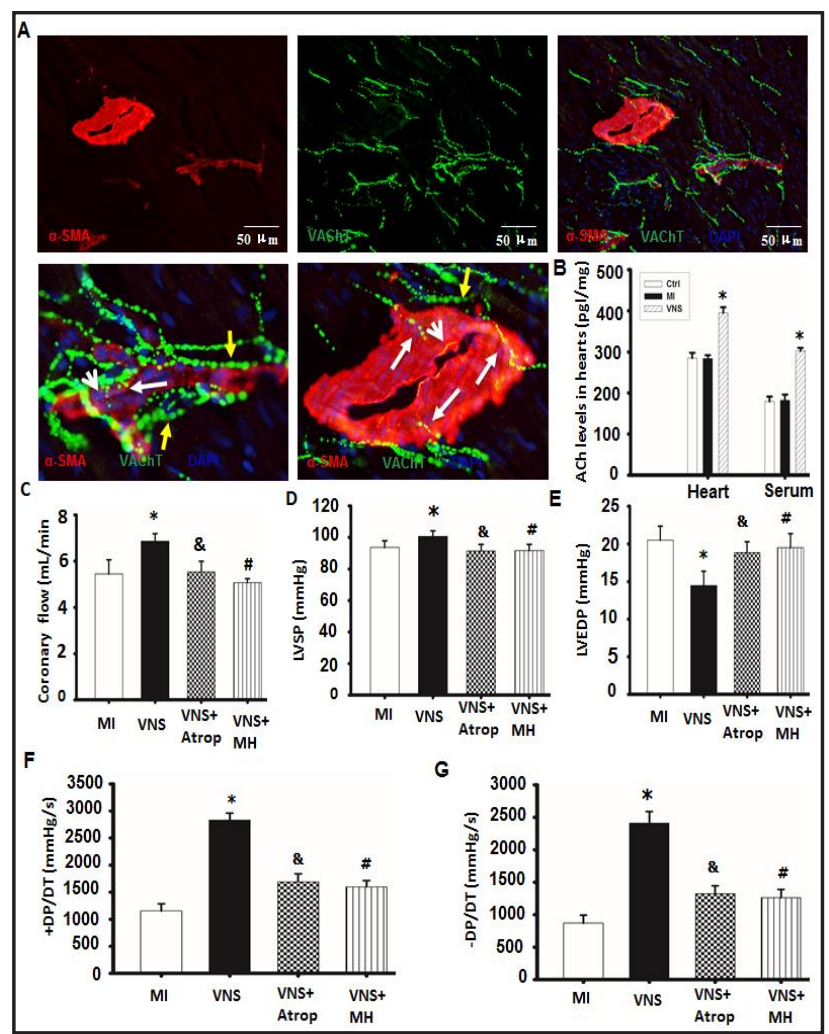

Fig. 1. VNS increased coronary blood flow and heart function. (A) Double immuostaining of a-SMA for VSMCs and VAChT for parasympathetic nerve, showing that vagal innervation was around the large and small coronary arteries with partially extention from adventitia (yellow arrow) to tunica media (white long arrow), and even to intima (white short arrow). Green color: VAChT; red color: a-SMA; Blue color: DAPI-labeled nuclei; Arrow: VAChT; Ad: adventitia; M: Media; L: lumen. (B) ELISA for detecting ACh levels in hearts tissues and serum of rats. ${ }^{*} \mathrm{P}=0.0047$ vs. $\mathrm{MI}, \mathrm{n}=6$. (C) Using Langendroff perfused heart system, coronary blood flows were evaluated in VNStreated hearts with simultaneous application of atropine $\left(10 \mathrm{mg} / \mathrm{kg}\right.$, ip) or mecamylamine $\left(10 \mathrm{mg} / \mathrm{kg}\right.$, ip). ${ }^{*} \mathrm{P}<0.05$ vs. MI; ${ }^{\circledR} \mathrm{P}<0.05$ vs. VNS; ${ }^{\#} \mathrm{P}<0.05$ vs. VNS ( $\left.=6\right)$. (D-G) VNS improved the left ventricular (LV) function of infarcted hearts. $\mathrm{LV}$ function of infarcted hearts was measured under resting conditions 14 days after treatment. (D) Left ventricular systolic pressure (LVSP). (E) Left ventricular end-diastolic pressure (LVEDP). (F, G) Rate of rise and fall of ventricular pressure $\left(+\mathrm{dP} / \mathrm{dt}_{\max }(\mathrm{F})\right)$ and $\left.-\mathrm{dP} / \mathrm{dt}_{\max }(\mathrm{G})\right) .{ }^{*} \mathrm{P}<0.05$ vs. MI;

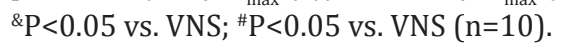


Fig. 2. VNS induced angiogenesis through $\mathrm{m} / \mathrm{n}$-ACh-R. Immunostaining of CD31 and $\alpha$-SMA to show the vessel density in infarcted heart 14 days after VNS. (B) Quantification of CD31 positive vessel density as indicated. ${ }^{*} \mathrm{P}<0.05$ vs. $\mathrm{MI} ;{ }^{\&} \mathrm{P}<0.05$ vs. VNS; ${ }^{*} \mathrm{P}<0.05$ vs. VNS $(\mathrm{n}=6)$. (C) Quantification of $\alpha$-SMA positive vessel density as indicated. ${ }^{*} \mathrm{P}<0.05$ vs. MI; ${ }^{\circledR} \mathrm{P}<0.05$ vs. VNS; ${ }^{\#} \mathrm{P}<0.05$ vs. VNS ( $\left.\mathrm{n}=6\right)$. Atrop indicates atropine, $10 \mathrm{mg} / \mathrm{Kg}, \mathrm{ip}$ ); $\mathrm{MH}$ indicates mecamylamine $(10 \mathrm{mg} / \mathrm{Kg}, \mathrm{ip})$.

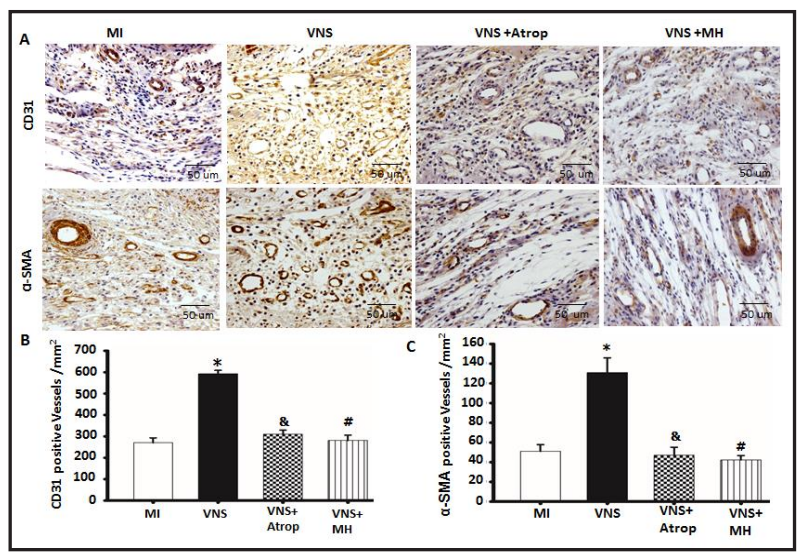

Fig. 3. The VEGF and VEGFR expression in infarcted hearts following the VNS. (A) VEGF-A and VEGF-B were induced in infarcted hearts 3 days after VNS. ${ }^{*} \mathrm{P}<0.05$ vs. MI; ${ }^{\circledR} \mathrm{P}<0.05$ vs. VEGF-A; $" \mathrm{P}<0.05$ vs. VEGF-B (n=6). (B) Flt1 and Flk1 were induced in infarcted hearts following the VNS. ${ }^{*} \mathrm{P}<0.05$ vs. $\mathrm{MI}$; ${ }^{\circledR} \mathrm{P}<0.05$ vs. Flk1 (n=6). (C) Double immuostaining of a-SMA and VEGF-A/B, showing that larger vessels of infarction areas of VNS-treated hearts by immunostaining, Green color: VEGF-A or VEGF-B; red color: a-SMA; Blue color: DAPI-labeled nuclei. (D)Typical pictures of VEGF-A or VEGF-B expressions were shown in infarction areas of small coronary vessels of VNS-treated hearts. Black arrow indicates VEGF-A; Red arrow indicates VEGF-B. (E, F) VNS-induced VEGF protein expression in infarcted heart tissues. Total proteins were extracted followed by western blot to detect the expression of VEGF as indicated. The protein levels were quantified by normalizing to the internal control $\alpha$-tubulin. ${ }^{*} \mathrm{P}<0.05$ vs. MI; ${ }^{\circledR} \mathrm{P}<0.05$ vs. VNS; ${ }^{~} \mathrm{P}<0.05$ vs. VNS; $\mathrm{n}=6$. Atrop indicates atropine, $10 \mathrm{mg} / \mathrm{Kg}$,ip); $\mathrm{MH}$ indicates mecamylamine $(10 \mathrm{mg} / \mathrm{Kg}, \mathrm{ip})$.

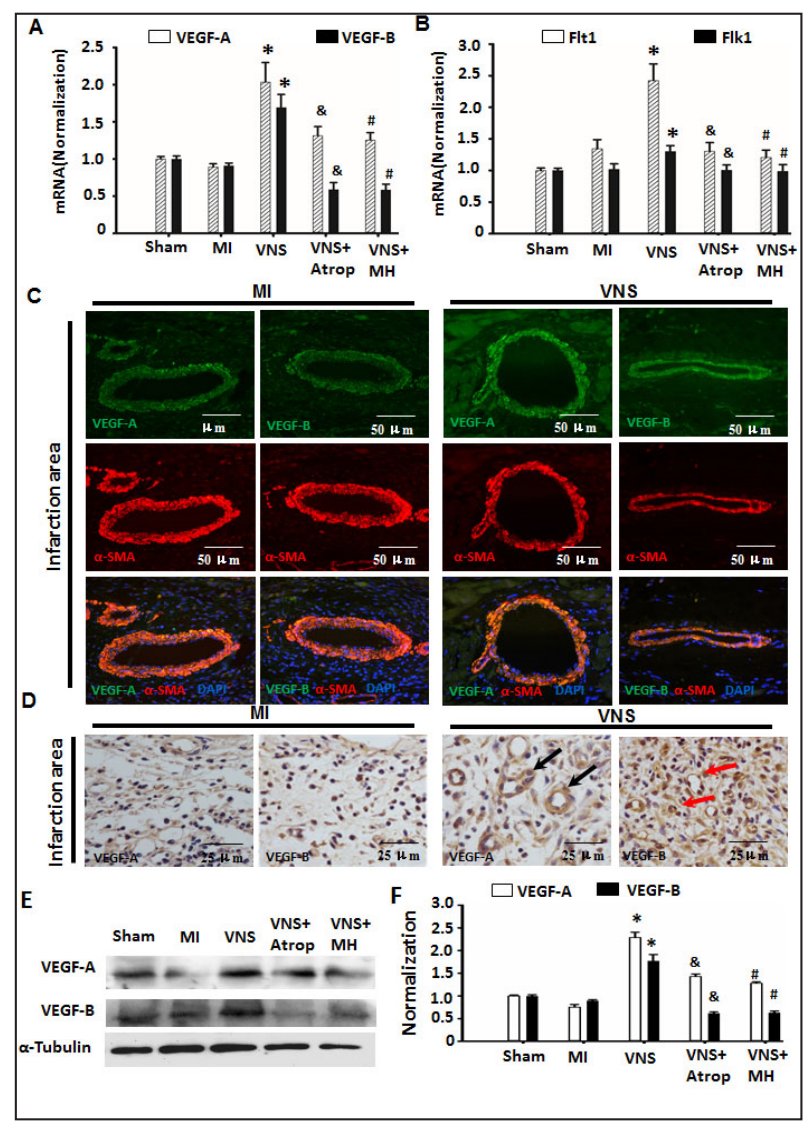

Since VNS promoted m3-ACh-R and $\alpha 7$-nACh expression in the infarcted hearts (Fig. 4C4D), we sought to determine if VNS-induced VEGF-A/B expression in coronary vessels was associated with m3-ACh-R and $\alpha 7-n A C h-R$. Thus, atropine (10 mg/kg, ip) or mecamylamine $(10 \mathrm{mg} / \mathrm{kg}$, ip) were used to block Ach receptor activity $1 \mathrm{~h}$ before the VNS treatment. As shown in Fig. 4D, both atropine and mecamylamine abolished VNS-induced VEGF-A/B expression, suggesting that m3ACh-R and $\alpha 7-n A C h R$ activation was essential for VNSmediated VEGF-A/B expression.

VNS-induced VEGF was essential for the angiogenesis and arteriogenesis in infarcted hearts

To determine if VNS-induced VEGF-A/B play roles in angiogenesis and arteriogenesis, we knocked down either VEGF-A or VEGF-B using adenoviral delivery of their shRNA in 
infarcted hearts prior to VNS. As shown in Fig. 5, Knockdown of either VEGF-A or VEGF-B decreased the numbers of both CD31-positive microvessels and $\alpha$-SMA-positive arteries. Importantly, CD31-positive capillary density was lower in hearts with knockdown of VEGF-A than VEGF-B (Fig. 5A-5B). Conversely, $\alpha$-SMApositive arterial density was lower in hearts with knockdown of VEGF-B than VEGF-A (Fig. 5A-5C). These effects were abrogated by VEGF receptor antagonist AMG 706 (Fig. 5A-5C), further confirming that VNSinduced angiogenesis and arteriogenesis were regulated by VEGF-A and VEGF-B.

Functionally, adenoviral delivery of VEGF-A and VEGF-B shRNA or administration of AMG706 abolished the beneficial effects of VNS on coronary blood flows (Fig. 5D), consisting with the changes in angiogenesis and arteriogenesis as shown in Fig. 5. These data indicated that the improvement of VNS-

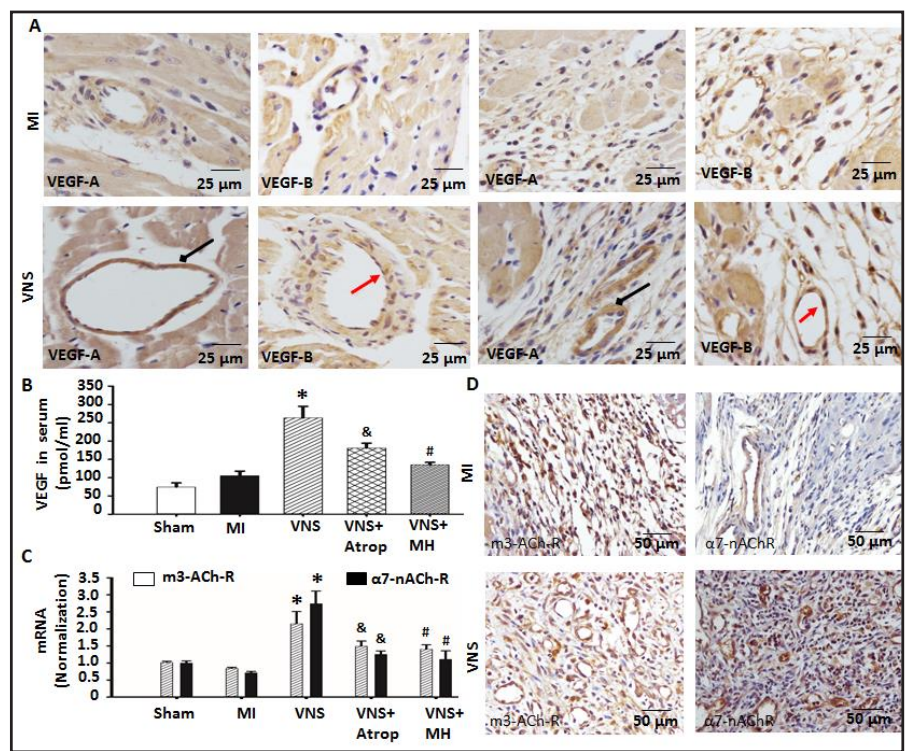

Fig. 4. VEGF expressions were located in the coronary vessels of peri-infarcted hearts 3 days after VNS. (A) Typical pictures of VEGF-A or VEGF-B expressions were shown in peri-infarction areas of small and large coronary vessels of VNS-treated hearts. Black arrow indicates VEGF-A; Red arrow indicates VEGF-B. (B) ELISA for detecting the VEGF level in rat serum. ${ }^{*} \mathrm{P}<0.05$ vs. MI; \& $\mathrm{P}<0.05$ vs. VNS; "P<0.05 vs. VNS; $\mathrm{n}=6$. (C) Real-time PCR showed the increased the expressions of m3ACh-R and $\alpha 7-n A C h R$ in the infarcted hearts by VNS, the specific effects could be abolished by atropine (Atrop, $10 \mathrm{mg} / \mathrm{kg}$, ip) or mecamylamine (MH, $10 \mathrm{mg} / \mathrm{Kg}$, ip). $\mathrm{n}=3,{ }^{*} \mathrm{P}<0.05 \mathrm{vs}$.MI; ${ }^{\mathrm{P}}<00.05 \mathrm{vs}$.VNS; $\mathrm{P}<0.05$ vs.VNS. (D) Typical image of the increased expressions of m3-AChR and a7-nAChR was found in infarction areas from VNS-treated hearts as determined by using immunostaining. was attributable to VEGFs/VEGFR-induced angiogenesis and arteriogenesis.

\section{VEGF-A was more potent than VEGF-B in inducing angiogenesis}

VEGF promotes new capillary formation by inducing EC sprouting, proliferation and migration $[17,18]$. To further determine if VNS-induced VEGF-A and VEGF-B were involved in angiogenesis of infarcted hearts, in vitro angiogenesis was assessed by measuring the capillary tube-like formation of human cardiac microvascular endothelial cells (HCMECs) and human coronary artery endothelial cells (HCAECs) on a nutrient-rich extracellular matrix gel. As shown in Fig. 6A, ACh-conditioned HCAEC culture medium ( $\left.{ }^{\mathrm{HCAECs}} \mathrm{CM}-\mathrm{GFP}-\mathrm{ACh}\right)$ promoted the formation of new tubes in vitro, which were associated with HCAECs, but not HCMECs. Knockdown of VEGF-A by shRNA or VEGFR blocker AMG706 abolished the effects of ${ }^{\mathrm{HCAECS}} \mathrm{CM}-\mathrm{ACh}$ on the tube formation (Fig. 6B-6C). It appeared that knockdown of VEGF-B

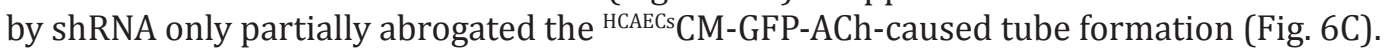

In addition, VEGF-A markedly promoted HCAEC proliferation while both VEGFA and VEGF-B induced HCAECs migration (Fig. 6D and 6E), indicating the synergetic action of VEGF-A and VEGF-B in angiogenesis. Similarly, ACh-conditioned VSMC culture medium ( ${ }^{\text {HVSMCS }} \mathrm{CM}$-GFP-ACh) also promoted HCAEC tube formation, but this effect was abolished by AMG706 or knockdown of VEGF-A or VEGF-B (Fig. 6F-4G). Interestingly, knockdown of VEGF-A almost completely abrogated the ${ }^{\mathrm{HVMCs}} \mathrm{CM}-\mathrm{GFP}-\mathrm{ACh}$-induced tube formation (Fig. $6 \mathrm{G})$. These data indicated that VNS-induced angiogenesis was due to the activation of VEGFs/ 
Fig. 5. VEGF involved in the angiogenesis in infarcted hearts 14 days after VNS. (A) Immunostaining of CD31 and $\alpha$-SMA for the analysis of vessel density in infarcted heart. (B) Quantitative analysis of CD31 and $\alpha$-SMA positive vessel density as indicated. ${ }^{*} \mathrm{P}<0.05$ vs. $\mathrm{MI} ;{ }^{\&} \mathrm{P}<0.05$ vs. VNS; ${ }^{\mathrm{P}}<0.05$ vs. VNS; ${ }^{\$} \mathrm{P}<0.05$ vs. VNS; $n=6$. (C) Coronary blood flows were evaluated using Langendroff perfused heart system in VNS-treated hearts with simultaneous application of AdshVEGF-A, Ad-shVEGF-B or AMG706 as indicated in Methods. ${ }^{*} \mathrm{P}<0.05$ vs. MI; ${ }^{\circledR} \mathrm{P}<0.05$ vs. VNS; ${ }^{\mathrm{P}}<0.05$ vs. VNS; $\$ \mathrm{P}<0.05$ vs. VNS; $\mathrm{n}=6$.

Fig. 6. VEGF-A and VEGF-B cooperatively regulated HCAEC proliferation, migration and tube formation. HCAECs showed greater capability of the formation of new tubes than HCMECs. HCAECs or HCMECs were seeded in 96-well plates coated with Matrigel and incubated in the indicated $\mathrm{CM}$, respectively. ${ }^{*} \mathrm{P}<0.05$ vs. HCAECs tubes group under ${ }^{\mathrm{HCAECS}} \mathrm{CM}-\mathrm{Ctrl}$; ${ }^{\&} \mathrm{P}<0.05$ vs. HCAECs tubes group under ${ }^{\mathrm{HCAECS} C M} \mathrm{C}$ Ctrl; ${ }^{\#} \mathrm{P}<0.05$ vs. HCAECs tubes group under ${ }^{\text {HCAECS }} \mathrm{CM}$-ACh. (B) VEGFR inhibitor AMG706 inhibited tube formation of HCAECs in condition medium of HCAECs exposed to ACh ( ${ }^{\mathrm{HCAECS}} \mathrm{CM}-\mathrm{ACh}$ ). ${ }^{*} \mathrm{P}<0.05$ vs. ${ }^{\mathrm{HCAECS} C M} \mathrm{CM}-\mathrm{Ctrl}$; ${ }^{\circledR} \mathrm{P}<0.05$ vs. HCAECS CM-ACh; ${ }^{\# P}<0.05$ vs. ${ }^{\text {HCAECs } C M-A c h ; ~}$ $n=12$. (C) Knockdown of VEGFA abolished EC tube formation of HCAECs in-

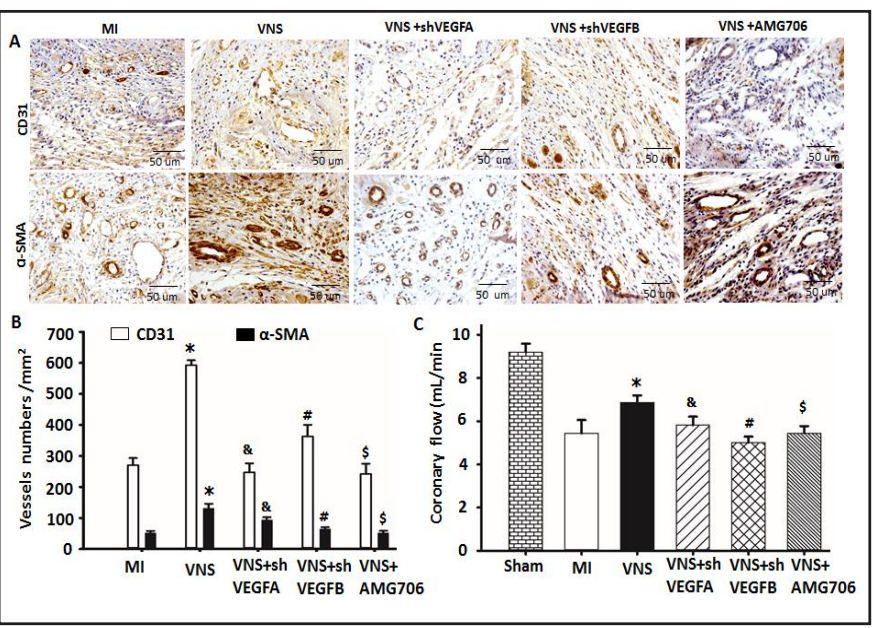
duced by ${ }^{\mathrm{HCAECS}} \mathrm{CM}-\mathrm{GFP}-\mathrm{ACh} .{ }^{\circledR} \mathrm{P}<0.05$ vs.

HCAECS CM-GFP; ${ }^{\$} \mathrm{P}<0.05$ vs. ${ }^{\mathrm{HCAECS}} \mathrm{CM}-\mathrm{GFP}-\mathrm{ACh} ;{ }^{\wedge} \mathrm{P}<0.05$ vs. ${ }^{\mathrm{HCAECS}} \mathrm{CM}-\mathrm{GFP}-\mathrm{Ach}$; $\mathrm{n}=12$. (D) CCK-8 assay showed that VEGF-A dosage-dependently promoted HCAEC proliferation significantly more effective than VEGFB. ${ }^{*} \mathrm{P}<0.05$ vs. the corresponding dosage of VEGF-B, $\mathrm{n}=6$. (E) Wound healing assay showed that VEGF-B dosage-dependently promoted HCAEC migration more effectively than VEGF-A. ${ }^{*} \mathrm{P}<0.05$ vs. the corresponding dosage of VEGF-A, n=6. (F) VEGFR inhibitor AMG706 obviously inhibited vascular-like tubes formation mediated by HCAECs under condition medium of HVSMCs exposed to ACh ( $\left.{ }^{\text {HvSMCs }} \mathrm{CM}-\mathrm{ACh}\right) . \mathrm{n}=12 .{ }^{*} \mathrm{P}<0.05$ vs. ${ }^{\text {HvsmCs }} \mathrm{CM}$-Ctrl; ${ }^{\&} \mathrm{P}<0.05$ vs. ${ }^{\text {HvsmCs }} \mathrm{CM}-\mathrm{ACh}$; ${ }^{\#} \mathrm{P}<0.05$ vs. ${ }^{\text {HvsmCs }} \mathrm{CM}-\mathrm{ACh}$. (G)Ad-shVEGF-A/B markedly abolished the vascular-like tube formation of HCAECs induced by ${ }^{\mathrm{HVSMCS}} \mathrm{CM}-\mathrm{GFP}-\mathrm{ACh} . \mathrm{n}=12$. ${ }^{\circledR} \mathrm{P}<0.05$ vs. ${ }^{\mathrm{HVSMCs}} \mathrm{CM}-\mathrm{GFP}$; ${ }^{\$} \mathrm{P}<0.05$ vs. ${ }^{\text {HvSMCs }} \mathrm{CM}-\mathrm{GFP}-\mathrm{ACh}$; ${ }^{\wedge} \mathrm{P}<0.05$ vs. ${ }^{\text {HVSMCs }} \mathrm{CM}-\mathrm{GFP}-\mathrm{ACh}$. (H) CCK-8 assay showed that VEGF-B more obviously promoted HVSMCs proliferation than VEGF-A in dosage-dependent manner. $n=6$. ${ }^{*} \mathrm{P}<0.05$ vs. the corresponding dosage of VEGF-A. (I) Wound healing assay showed that VEGF-A more obviously promoted HVSMCs migration than VEGF-B in dosage-dependent manner. $n=6$. ${ }^{*} \mathrm{P}<0.05$ vs. the corresponding dosage of VEGF-A. 
VEGFR signaling in coronary artery endothelial cells of infarcted hearts.

The synergetic effects of VEGF-A and VEGF-B on HVSMC proliferation and migration

Arteriogenesis is accompanied by differentiation, proliferation, and migration of VSMCs [30]. To test if VNSinduced VEGF-A and VEGF-B regulate VSMC phenotype in arteriogenesis of infarcted hearts, we used CCK-8 assay to analyze VSMC proliferation when exposed to different doses of VEGF-A or VEGF-B. We found that VEGF-A and VEGF-B dosage-dependently promoted VSMC proliferation (Fig. 6H). VEGF-B appeared to have a greater effect in VSMC proliferation than VEGF-A. Moreover, wound healing assay showed that both VEGF-A and VEGF-B induced VSMC migration in dose-dependent manner (Fig. 6I) although VEGF-A exhibited a stronger effect on VSMC migration as compared with VEGF-B. Taken together, VEGF-B promoted VSMC proliferation while VEGF-A induced VSMC migration, indicating a cooperative function of VEGF-A and VEGF-B in the VNS-mediated arteriogenesis.

Sp1 transcription factor involved in VNS-induced VEGF-A/B expression

It is known that PI3K/ Akt, p38 MAPK, ERK1/2, and eNOS signaling regulate VEGF expression in ECs, endothelial progenitor cells (EPCs) and mesenchymal stem cells (MSCs) $[24,25,28,32]$. To test if any of these signaling pathways is involved in VNS-induced VEGF$\mathrm{A} / \mathrm{B}$ expression, we used pathway-specific inhibitors to block the above-mentioned signal individually and observe if Ach-induced VEGF expression can be altered. We found that typical PI3K/Akt inhibitors both Wortmannin and LY294002 decreased the Ach-mediated VEGFA and VEGF-B expression (Fig. 7A-7B), suggesting PI3K signaling regulated their expression. Indeed, Ach significantly increased the phosphorylated Akt level in ECs although the

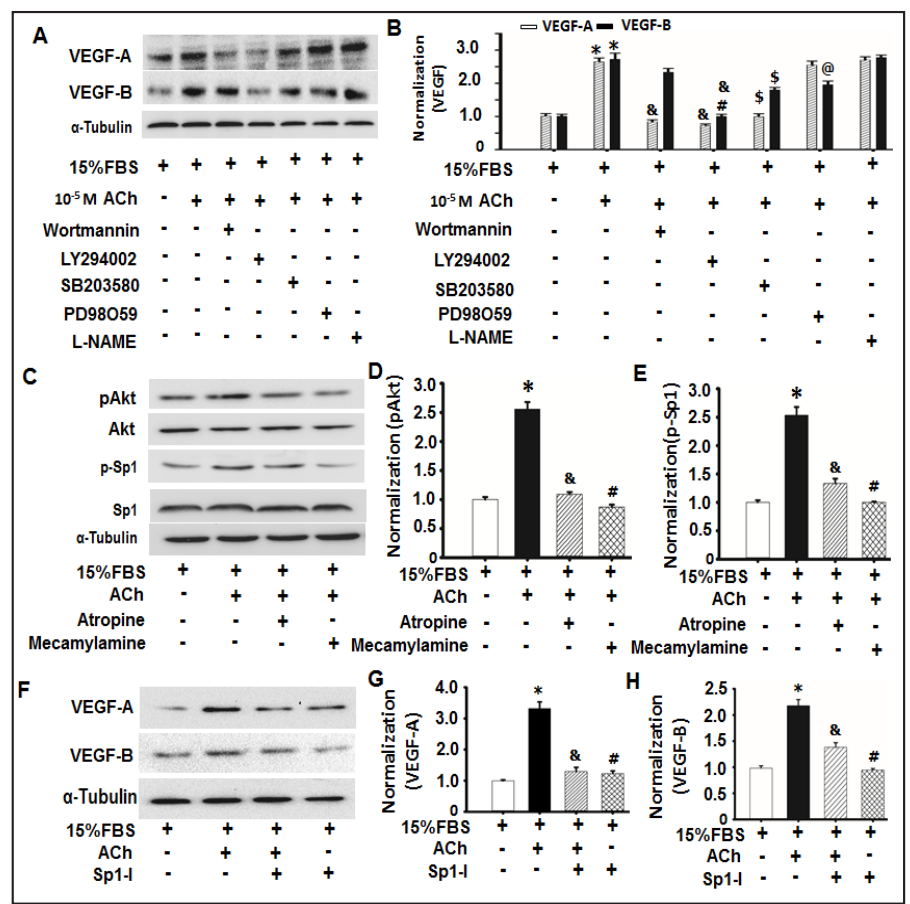

Fig. 7. VEGF expression was regulated by PI3K/Akt signaling and downstream Sp1. Signaling pathways mediated the ACh-induced VEGF expression were assessed by pathway-specific inhibitors as indicated. Western blot was used to detect ACh-induced VEGF expression in HCAECs following the treatment with Wortmannin

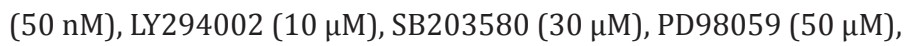
L-NAME $(300 \mu \mathrm{M})$, respectively. $\alpha$-tubulin served as an internal control. (B) Quantification of protein expression in HCAECs shown in A by normalizing to $\alpha$-tubulin. ${ }^{*} \mathrm{P}<0.05$ vs. $0 \mathrm{M} \mathrm{ACh}$; ${ }^{\circledR} \mathrm{P}<0.05$ vs. $10^{-5} \mathrm{M}$ ACh; ${ }^{\mathrm{P}}<0.05$ vs. PI3K/Akt inhibitor wortmannin; ${ }^{\$} \mathrm{P}<0.05$ vs. $10^{-5} \mathrm{M}$ ACh; ${ }^{\circledR} \mathrm{P}>0.05$ vs. $10^{-5} \mathrm{M}$ Ach; $\mathrm{n}=3$. (C) Phospho-Akt, total Akt, Sp1, and phosphor-Sp1 proteins in HCAECs were detected by Western blot. (D-E) Quantification of protein levels shown in C showed that the phosphorylation of Akt and Sp1 following ACh stimulation in HCAECs was abolished by mACh-R inhibitor atropine or nACh-R inhibitor mecamylamine. ${ }^{*} \mathrm{P}<0.05$ vs. Ctrl; ${ }^{\&} \mathrm{P}<0.05$ vs. $10^{-5} \mathrm{M}$ ACh; ${ }^{\text {P }}<0.05$ vs. $10^{-5} \mathrm{M}$ ACh; $\mathrm{n}=3$. (F) Sp1 was essential for ACh-induced VEGF-A and VEGF-B expression in HCAECs as detected by Western blot. (G-H) Quantification of protein levels shown in F (by normalized to $\alpha$-tubulin) showed that Sp1 specific inhibitor mithramycin A (Sp1-I, $1 \mu \mathrm{M}$ ) almost completely abolished the effect of ACh on VEGF-A and VEGF-B expression in HCAECs. ${ }^{*} \mathrm{P}<0.05$ vs. Ctrl; ${ }^{\circledR} \mathrm{P}<0.05$ vs. $10^{-5} \mathrm{M}$ ACh; ${ }^{\#} \mathrm{P}<0.05$ vs. $10^{-5} \mathrm{M}$ ACh; $\mathrm{n}=3$. 
total Akt level was not altered. However, mAChR inhibitor atropine and $\alpha 7-n A C h R$ blocker mecamylamine abolished the activation of Akt (Fig. 7C-7D). These data demonstrated that ACh induced VEGF expression through $\mathrm{m} / \mathrm{nAChR}-\mathrm{PI} 3 \mathrm{~K} / \mathrm{AKT}$ signal pathway.

Previous studies have shown that VEGF-A is regulated by transcription factor Sp1 [33]. To determine if AChinduced Akt phosphorylation causes Sp1 activation, and thus VEGF-A and VEGF-B gene transcription, total Sp1 (t-Sp1) and phosphorylated Sp1 (p-Sp1) were analyzed in HCAECs using western blot. As shown in Fig. 7C, ACh promoted the phosphorylation of transcription factor Sp1 ( $\mathrm{p}-\mathrm{Sp} 1)$ while not affecting its expression (Fig. 7E). However, atropine or mecamylamine almost completely blocked Ach-induced Sp1 phosphorylation. Importantly, Sp1 specific inhibitor mithramycin A abolished both VEGF-A and VEGF-B expression induced by ACh (Fig. 7F-7H). These results indicated that $\mathrm{ACh} / \mathrm{m} / \mathrm{nAChR} / \mathrm{Akt} / \mathrm{Sp} 1$ signaling cascade mediated the VEGF-A/B gene transcription in response to ACh.

\section{VNS improved cardiac structure and function}

To determine if VNS-induced angiogenesis and arteriogenesis promote cardiac repair and improve heart function in infracted hearts, AMG706 were injected i.p. or adenovirus expressing VEGF-A or VEGF-B shRNA were injected in the infarcted hearts following VNS. Masson's trichrome staining showed severe heart fibrosis due to myocardium infarction. However, VNS significantly decreased the heart fibrosis (Fig. 8A, 8C). Moreover, VNS reduced the infarct size (Fig. 8B), markedly increased LV wall thickness (Fig. 8D). Consistent with the in vitro findings, the beneficial effect of VNS was abolished by AMG706, VEGF-A or VEGF-B shRNA.

Functional analysis showed that LV function including LVSP, LVEDP, $+\mathrm{dP} / \mathrm{dt}_{\text {max }}$ and $-\mathrm{dP} /$ $\mathrm{dt}_{\max }$ was significantly improved in VNS-treated hearts as compared to the MI animals (Fig. 8E-8H). AMG706 or VEGF shRNA, however, reduced VNS-improved LV function (Fig. 8E-8H).

\section{Discussion}

Our studies made three novel observations. Firstly, we found that VNS-induced VEGFA/B expression cooperatively regulated angiogenesis and arteriogenesis in infarcted heart. Secondly, VNS-triggered angiogenesis and arteriogenesis improved the coronary function 
related to left ventricular performance. And lastly, the VEGF-A/B expression was regulated by the $\mathrm{ACh} / \mathrm{m} / \mathrm{nAChR} / \mathrm{Akt} / \mathrm{Sp} 1$ signal cascade.

Collateral artery growth or arteriogenesis is the primary approach for coronary arteries to maintain blood flow in the event of coronary arterial occlusions, being responsible for myocardium infarction [34]. An occluded artery is not normally replaced by one single large collateral vessel but rather by several smaller ones [30]. We found that VNS not only promoted angiogenesis characterized by the increased number of CD31 positive capillaries, but also induced the formation of $\alpha$-SMA positive arteriogenesis in the MI-hearts. Functionally, VNS improved coronary blood flow (CBF) and heart function. These data suggested that synergistic effects of angiogenesis and arteriogenesis involved in VNS-mediated heart repair.

Publicated data have shown that VEGF family members play crucial roles in the formation of collateral arteries involving the proliferation and migration of VSMCs, adventitial fibroblasts in addition to ECs [30, 35]. VNS promoted VEGF-A and VEGF-B expression in coronary artery VSMCs and ECs of the infarcted hearts, resulting in the increased numbers of both CD31 positive capillaries and $\alpha$-SMA positive arteries in vivo. Consistent with this observation, VEGF-A promoted HCAEC proliferation and HVSMC migration while VEGF-B induced HVSMC proliferation and HCAEC migration. Therefore, coordination of VEGF-A and VEGF-B appeared to better promote the repair of infarcted hearts through inducing both the angiogenesis and arteriogenesis after VNS.

Actually, coronary microvascular dysfunction, defined as impaired coronary flow reserve and/or coronary endothelial dysfunction, was associated with adverse cardiovascular events including death, nonfatal myocardial infarction, nonfatal stroke, and congestive heart failure [6]. Generally, the greater number of coronary arteries, the greater CBF [6, 28]. Our data documenting a relationship between CBF and VNS were consistent with other findings $[28,36]$. Regarding as its short-term effects, VNS, as a novel therapy for autonomic dysfunction, could directly perform vascular protection and vasodilation to improve coronary microvascular function, resulting from released ACh [37]. Furthermore, similar to the response of coronary vasculature to intracoronary infusions of VEGF [38], VNS could act as an adjuvant to increase CBF through activating VEGF, apart from released ACh. As for its long-term effects, expressions and releases of ACh-induced VEGF from both intima ECs and media VSMCs, as important providers of VEGF, maintained coronary endothelial cells function via stimulating angiogenesis in infracted hearts. Taken together, these data, along with previous findings that angiogenic factors induced coronary artery and microvessel formation in vivo $[39,40]$, suggested that VNS could promote angiogenic factors-mediated angiogenesis and arteriogenesis to improve coronary function and left heart performance, which contributed to better explain the increased long-term survival rates of HF [41].

Previous studied have shown that ACh protects cardiomyocytes through activating hypoxia-inducible factor $1 \alpha(\mathrm{HIF}-1 \alpha)$ [10]. Although HIF-1 $\alpha$ is a typical inducer for VEGF-A expression [42],P13K/Aktsignaling can increaseVEGF-Aexpression viaaHIF- $1 \alpha$-independent mechanism [43]. Our studies showed that ACh increased the Akt phosphorylation under normoxia condition, resulting in a higher phosphorylation of $\mathrm{Sp} 1$ and a greater expression of VEGF-A/B, comparable to p38MAPK-mediated Sp1 phosphorylation and VEGF-A expression [44]. Of interest, although Sp1 induced by ACh was important for the expression of both VEGF-A and VEGF-B, the Sp1-binding sequence is only present in the promoter region of VEGF-A, but not of VEGF-B. Therefore, other transcription factors are likely to be involved in Sp1-mediated VEGF-B expression, which may be investigated in the future.

The therapeutic expansion of blood vessel growth in patients suffering ischemic or infarcted diseases has become a challenge in clinical. In contrast to the promising results from animal studies and from a number of clinical phase I trials, several larger controlled studies testing VEGF-A, VEGF-C, VEGF-D, fibroblast growth factor 2 (FGF2), or FGF4 have shown that the gene therapy is safe despite the lack of clear benefit [45-49]. The main issues include: (1) the majority of experiments are performed with young healthy animals but target groups for arteriogenic therapy are elderly patients experiencing cardiovascular diseases; and (2) only one protein is applied for patients, which is probably the major problem in human acute

\section{KARGER}


MI $[50,51]$. Previous studies showed that VEGF-A promoted angiogenesis in the ischemia heart $[15,16]$, while VEGF-B acted as a coronary growth factor in transgenic rats without inducing angiogenesis, vascular leak, or inflammation [52]. Our present studies have shown that the synergistic effect of VEGF-A and VEGF-B induced by VNS may better promote the angiogenesis and arteriogenesis in infarcted hearts, which provided a novel and valuable approach for gene therapy of cardiovascular diseases.

Clinically, VNS have been widely recognized as typical cholinergic anti-inflammatory and anti-adrenergic activities. Herein, the beneficial effects of VNS on cardiac angiogenesis and arteriogenesis from coronary artery, cardiac function and remodeling of HF rats contributed to the synergistic effect of VEGF-A and VEGF-B. Although radio-controlled pulse generator to stimulate the vagal nerve was not used in the study $[2,44]$, the method of VNS treatment used in the present study has been also frequently adopted in animal experimental $[53,54]$. And the therapeutic modality used in the present study also brought a long-term favorable prognosis of HF through manipulating coronary artery. In a word, VNS should serve as a candidate choice of clinical treatment for MI and HF patients.

Taken together, our studies demonstrated that VNS improves coronary function and heart function through promoting angiogenesis and arteriogenesis in the infracted heart by activating both VEGF-A and VEGF-B signaling, which were regulated by the P13K/Akt-Sp1 signaling cascade.

\section{Acknowledgements}

This study was supported by grants from the National Natural Science Foundation of China (81670272, 81170095 to J.M.T), Hubei Science\& Technology Department Foundation (2014CFB644, 2016CFA027 to J.M.T), Hubei University of Medicine Innovation Team (FDFR201601 to J.M.T) and National Institutes of Health (HL119053, HL123302, and HL135854 to S.Y.C.).

\section{Disclosure Statement}

All authors have read and approved the manuscript, and there is no ethical problem or conflict of interests.

\section{References}

1 Lim GB: Heart failure: Vagal nerve stimulation in chronic heart failure. Nat Rev Cardiol 2016;13:312.

$>2$ Li M, Zheng C, Sato T, Kawada T, Sugimachi M, Sunagawa K: Vagal nerve stimulation markedly improves long-term survival after chronic heart failure in rats. Circulation 2004;109:120-124.

-3 Shen MJ, Shinohara T, Park HW, Frick K, Ice DS, Choi EK, Han S, Maruyama M, Sharma R, Shen C, Fishbein MC, Chen LS, Lopshire JC, Zipes DP, Lin SF, Chen PS: Continuous low-level vagus nerve stimulation reduces stellate ganglion nerve activity and paroxysmal atrial tachyarrhythmias in ambulatory canines. Circulation 2011;123:2204-2212.

4 Martelli D, McKinley MJ, McAllen RM: The cholinergic anti-inflammatory pathway: a critical review. AutonNeurosci 2014;182:65-69.

5 Li P, Liu H, Sun P, Wang X, Wang C, Wang L, Wang T.: Chronic vagus nerve stimulation attenuates vascular endothelial impairments and reduces the inflammatory profile via inhibition of the NF- $\kappa B$ signaling pathway in ovariectomized rats. Exp Gerontol 2016;74:43-55.

6 Niccoli G, Scalone G, Lerman A, Crea F: Coronary microvascular obstruction in acute myocardial infarction. Eur Heart J 2016;37:1024-1033. 


\section{Cellular Physiology Cell Physiol Biochem 2018;48:433-449 \begin{tabular}{l|l} 
DOI: 10.1159/000491775 & $\begin{array}{l}\text { O } 2018 \text { The Author(s). Published by S. Karger AG, Basel } \\
\text { www.karger.com/cpb }\end{array}$
\end{tabular}}

Lv et al.: VNS Arteriogenesis VEGF-A/B Infarcted Heart

7 Yu JG, Song SW, Shu H, Fan SJ, Liu AJ, Liu C, Guo W, Guo JM, Miao CY, Su DF: Baroreflex deficiency hampers angiogenesis after myocardial infarction via acetylcholine- $\alpha 7$-nicotinic ACh receptor in rats. Eur Heart J 2013;34:2412-2420.

8 Pillai S, Chellappan S: $\alpha 7$ nicotinic acetylcholine receptor subunit in angiogenesis and epithelial to mesenchymal transition. Curr Drug Targets 2012;13:671-679.

-9 Pillay CV, Reid JV: Histochemical localization of acetylcholinesterase in the wall of cardiac blood vessels in the baboon, dog and vervet monkey. Basic Res Cardiol 1982;77:213-219.

10 Kakinuma Y, Ando M, Kuwabara M, Katare RG, Okudela K, Kobayashi M, Sato T: Acetylcholine from vagal stimulation protects cardiomyocytes against ischemia and hypoxia involving additive non-hypoxic induction of HIF-1alpha. FEBS Lett 2005;579:2111-2118.

11 Akiyama T, Yamazaki T: Effects of right and left vagal stimulation on left ventricular acetylcholine levels in the cat. ActaPhysiol Scand 2001;172:11-16.

12 Cooke JP, GhebremariamYT. Endothelial nicotinic acetylcholine receptors and angiogenesis. Trends Cardiovasc Med 2008;18:247-253.

13 Coote JH: Myths and realities of the cardiac vagus. J Physiol 2013;591:4073-4085.

14 Zhao M, He X, Bi XY, Yu XJ, Gil Wier W, Zang WJ: Vagal stimulation triggers peripheral vascular protection through the cholinergic anti-inflammatory pathway in a rat model of myocardial ischemia/reperfusion. Basic Res Cardiol 2013;108:345.

15 Arany Z, Foo SY, Ma Y, Ruas JL, Bommi-Reddy A, Girnun G, Cooper M, Laznik D, Chinsomboon J, Rangwala SM, Baek KH, Rosenzweig A, Spiegelman BM: HIF-independent regulation of VEGF and angiogenesis by the transcriptional coactivator PGC-1alpha.Nature 2008;451:1008-1012.

16 Zhao T, Zhao W, Chen Y, Ahokas RA, Sun Y: Vascular endothelial growth factor (VEGF)-A: role on cardiac angiogenesis following myocardial infarction. Microvasc Res 2010;80:188-194.

17 Lähteenvuo JE, Lähteenvuo MT, Kivelä A, Rosenlew C, Falkevall A, Klar J, Heikura T, Rissanen TT, Vähäkangas E, Korpisalo P, Enholm B, Carmeliet P, Alitalo K, Eriksson U, Ylä-Herttuala S: Vascular endothelial growth factor-B induces myocardium-specific angiogenesis and arteriogenesis via vascular endothelial growth factor receptor-1- and neuropilin receptor-1-dependent mechanisms.Circulation 2009;119:845-856.

18 Pipp F, Heil M, Issbrücker K, Ziegelhoeffer T, Martin S, van den Heuvel J, Weich H, Fernandez B, Golomb G, Carmeliet P, Schaper W, Clauss M: VEGFR-1-selective VEGF homologue PIGF is arteriogenic: evidence for a monocyte-mediated mechanism. Circ Res 2003;92:378-385.

19 Tammela T, Enholm B, Alitalo K, Paavonen K: The biology of vascular endothelial growth factors. Cardiovasc Res 2005;65:550-563.

20 Tang JM, Wang JN, Zhang L, Zheng F, Yang JY, Kong X, Guo LY, Chen L, Huang YZ, Wan Y, Chen SY: VEGF/ SDF-1 promotes cardiac stem cell mobilization and myocardial repair in the infarcted heart. Cardiovasc Res 2011;91:402-411.

21 Polverino A, Coxon A, Starnes C, Diaz Z, DeMelfi T, Wang L, Bready J, Estrada J, Cattley R, Kaufman S, Chen D, Gan Y, Kumar G, Meyer J, Neervannan S, Alva G, Talvenheimo J, Montestruque S, Tasker A, Patel V, Radinsky R, Kendall R: AMG 706, an oral, multikinase inhibitor that selectively targets vascular endothelial growth factor, platelet-derived growth factor, and kit receptors, potently inhibits angiogenesis and induces regression in tumor xenografts. Cancer Res 2006;66:8715-8721.

22 Tang JM, Luo B, Xiao JH, Lv YX, Li XL, Zhao JH, Zheng F, Zhang L, Chen L, Yang JY, Guo LY, Wang L, Yan YW, Pan YM, Wang JN, Li DS, Wan Y, Chen SY: VEGF-A promotes cardiac stem cell engraftment and myocardial repair in the infarcted heart. Int J Cardiol 2015;183:221-231.

23 Reichelt ME, Willems L, Hack BA, Peart JN, Headrick JP: Cardiac and coronary function in the Langendorffperfused mouse heart model. Exp Physiol 2009;94:54-70.

24 DeCicco-Skinner KL, Henry GH, Cataisson C, Tabib T, Gwilliam JC, Watson NJ, Bullwinkle EM, Falkenburg L, O'Neill RC, Morin A, Wiest JS: Endothelial cell tube formation assay for the in vitro study of angiogenesis. J Vis Exp $2014 ; 91: \mathrm{e} 51312$.

25 Cao T, Zhang L, Yao LL, Zheng F, Wang L, Yang JY, Guo LY, Li XY, Yan YW, Pan YM, Jiang M, Chen L, Tang JM, Chen SY, Wang JN: S100B promotes injury-induced vascular remodeling through modulating smooth muscle phenotype. Biochim Biophys Acta 2007;1863:2772-2782. 


\section{Cellular Physiology Cell Physiol Biochem 2018;48:433-449 \begin{tabular}{l|l} 
DOI: 10.1159/000491775 & $\begin{array}{l}\text { O } 2018 \text { The Author(s). Published by S. Karger AG, Basel } \\
\text { www.karger.com/cpb }\end{array}$
\end{tabular}}

Lv et al.: VNS Arteriogenesis VEGF-A/B Infarcted Heart

-26 Rossi J, Santamäki P, Airaksinen MS, Herzig KH: Parasympathetic innervation and function of endocrine pancreas requires the glial cell line-derived factor family receptor alpha2 (GFRalpha2). Diabetes 2005;54:1324-1330.

27 Grauss RW, Winter EM, van Tuyn J, Pijnappels DA, Steijn RV, Hogers B, van der Geest RJ, de Vries AA, Steendijk P, van der Laarse A, Gittenberger-de Groot AC, Schalij MJ, Atsma DE: Mesenchymal stem cells from ischemic heart disease patients improve left ventricular function after acute myocardial infarction. Am J Physiol Heart Circ Physiol 2007;293:H2438- H2447.

28 Camici PG, d'Amati G, Rimoldi O: Coronary microvascular dysfunction: mechanisms and functional assessment. Nat Rev Cardiol 2015;12:48-62.

29 Klabunde RE, Ryan KM, Paxson CE: Acute hyperglycaemia does not alter coronary vascular function in isolated, perfused rat hearts.Diabetes Obes Metab 2007;9:697-705.

30 Heil M, Schaper W: Influence of mechanical, cellular, and molecular factors on collateral artery growth (arteriogenesis).Circ Res 2004; 95:449-458.

-31 Hao X, Månsson-Broberg A, Grinnemo KH, Siddiqui AJ, Dellgren G, Brodin LA, Sylvén C: Myocardial angiogenesis after plasmid or adenoviral VEGF-A(165) gene transfer in rat myocardial infarction model. Cardiovasc Res 2007;73:481-487.

32 Couto GK, Britto LR, Mill JG, Rossoni LV: Enhanced nitric oxide bioavailability in coronary arteries prevents the onset of heart failure in rats with myocardial infarction. J Mol Cell Cardiol 2015;86:110-120.

-33 Lin HH, Lai SC, ChauLY: Heme oxygenase-1/carbon monoxide induces vascular endothelial growth factor expression via p38 kinase-dependent activation of Sp1.J Biol Chem 2011;286:3829-3838.

-34 Pöling J, Szibor M, Schimanski S, Ingelmann ME, Rees W, Gajawada P, Kochfar Z, Lörchner H, Salwig I, Shin JY, Wiebe K, Kubin T, Warnecke H, Braun T: Induction of smooth muscle cell migration during arteriogenesis is mediated by Rap2. Arterioscler Thromb Vasc Biol 2011;31:2297-305.

-35 Zafar MI, Zheng J, Kong W, Ye X, Gou L, Regmi A, Chen LL: The role of vascular endothelial growth factor-B in metabolic homoeostasis: current evidence. Biosci Rep 2017;37: pii: BSR20171089.

36 Li DJ, Zhao T, Xin RJ, Wang YY, Fei YB, Shen FM: Activation of $\alpha 7$ nicotinic acetylcholine receptor protects against oxidant stress damage through reducing vascular peroxidase-1 in a JNK signaling-dependent manner in endothelial cells.Cell Physiol Biochem 2014;33:468-478.

37 Amenta F, Ferrante F, CavallottiC: Acetylcholinesterase containing nerve fibres in coronary circulation. Cardiovasc Res 1981;15:171-174.

-38 Laham RJ, Li J, Tofukuji M, Post M, Simons M, Sellke FW: Spatial heterogeneity in VEGF-induced vasodilation: VEGF dilates microvessels but not epicardial and systemic arteries and veins. Ann Vasc Surg 2003;17:245-252.

39 Tian X, Hu T, Zhang H, He L, Huang X, Liu Q Yu W, He L, Yang Z, Yan Y, Yang X, Zhong TP, Pu WT, Zhou B: Vessel formation. De novo formation of a distinct coronary vascular population in neonatal heart. Science 2014;345:90-94.

40 Tillmanns J, Rota M, Hosoda T, Misao Y, Esposito G, Gonzalez A, Vitale S, Parolin C, Yasuzawa-Amano S, Muraski J, De Angelis A, Lecapitaine N, Siggins RW, Loredo M, Bearzi C, Bolli R, Urbanek K, Leri A, Kajstura J, Anversa P: Formation of large coronary arteries by cardiac progenitor cells. Proc Natl Acad Sci U S A 2008;105:1668-1673.

41 Nishizaki A, Sakamoto K, Saku K, Hosokawa K, Sakamoto T, Oga Y, Akashi T, Murayama Y, Kishi T, Ide T, Sunagawa K: Optimal Titration Is Important to Maximize the Beneficial Effects of Vagal Nerve Stimulation in Chronic Heart Failure. J Card Fail 2016; 22:631-638.

42 Güzel D, Dursun AD, Fiçıcılar H, Tekin D, Tanyeli A, Akat F, Topal Çelikkan F, Sabuncuoğlu B, Baştuğ M: Effect of intermittent hypoxia on the cardiac HIF-1/VEGF pathway in experimental type 1 diabetes mellitus. Anatol J Cardiol 2016;16:76-83.

43 Pore N, Liu S, Shu HK, Li B, Haas-Kogan D, Stokoe D, Milanini-Mongiat J, Pages G, O’Rourke DM, Bernhard E, Maity A: Sp1 is involved in Akt-mediated induction of VEGF expression through an HIF-1-independent mechanism. Mol Biol Cell 2004; 15:4841-4853.

-44 Hu H, Han T, Zhuo M, Wu LL, Yuan C, Wu L, Lei W, Jiao F, Wang LW: Elevated COX-2 Expression Promotes Angiogenesis Through EGFR/p38-MAPK/Sp1-Dependent Signalling in Pancreatic Cancer. Sci Rep 2017;7:470. 


\section{Cellular Physiology Cell Physiol Biochem 2018;48:433-449

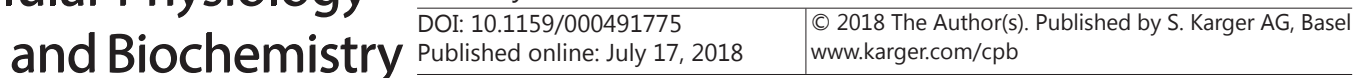

Lv et al.: VNS Arteriogenesis VEGF-A/B Infarcted Heart

45 Hedman M, Muona K, Hedman A, Kivelä A, Syvänne M, Eränen J, Rantala A, Stjernvall J, Nieminen MS, Hartikainen J, Ylä-Herttuala S: Eight-year safety follow-up of coronary artery disease patients after local intracoronary VEGF gene transfer. Gene Ther 2009;16:629-634.

46 Marui A, Tabata Y, Kojima S, Yamamoto M, Tambara K, Nishina T, Saji Y, Inui K, Hashida T, Yokoyama S, Onodera R, Ikeda T, Fukushima M, Komeda M: A novel approach to therapeutic angiogenesis for patients with critical limb ischemia by sustained release of basic fibroblast growth factor using biodegradable gelatin hydrogel: an initial report of the phase I-IIa study. Circ J 2007;71:1181-1186.

47 Rosengart TK, Bishawi MM, Halbreiner MS, Fakhoury M, Finnin E, Hollmann C, Shroyer AL, Crystal RG: Long-term follow-up assessment of a phase 1 trial of angiogenic gene therapy using direct intramyocardial administration of an adenoviral vector expressing the VEGF121 cDNA for the treatment of diffuse coronary artery disease. Hum Gene Ther 2013;24:203-208.

-48 Hartikainen J, Hassinen I, Hedman A, Kivelä A, Saraste A, Knuuti J, Husso M, Mussalo H, Hedman M, Rissanen TT, Toivanen P, Heikura T, Witztum JL, Tsimikas S, Ylä-Herttuala S: Adenoviral intramyocardial VEGF-D $\Delta \mathrm{N} \Delta \mathrm{C}$ gene transfer increases myocardial perfusion reserve in refractory angina patients: a phase I/IIa study with 1-year follow-up. Eur Heart J 2017;38:2547-2555.

49 Lavu M, Gundewar S, Lefer DJ: Gene therapy for ischemic heart disease. J Mol Cell Cardiol 2011;50:742-

-50 Kupatt C, Hinkel R, Pfosser A, El-Aouni C, Wuchrer A, Fritz A, Globisch F, Thormann M, Horstkotte J, Lebherz C, Thein E, Banfi A, Boekstegers P: Cotransfection of vascular endothelial growth factor-A and plateletderived growth factor-B via recombinant adeno-associated virus resolves chronic ischemic malperfusion role of vessel maturation. J Am Coll Cardiol 2010;56:414-422.

-51 Stewart DJ, Kutryk MJ, Fitchett D, Freeman M, Camack N, Su Y, Della Siega A, Bilodeau L, Burton JR, Proulx G, Radhakrishnan S: NORTHERN Trial Investigators: VEGF gene therapy fails to improve perfusion of ischemic myocardium in patients with advanced coronary disease: results of the NORTHERN trial. Mol Ther 2009;17:1109-1115.

52 Bry M, Kivelä R, Holopainen T, Anisimov A, Tammela T, Soronen J, Silvola J, Saraste A, Jeltsch M, Korpisalo P, Carmeliet P, Lemström KB, Shibuya M, Ylä-Herttuala S, Alhonen L, Mervaala E, Andersson LC, Knuuti J, Alitalo K: Vascular endothelial growth factor-B acts as a coronary growth factor in transgenic rats without inducing angiogenesis, vascular leak, or inflammation. Circulation 2010;122:1725-1733.

53 De Ferrari G.M: Vagal Stimulation in Heart Failure. J of Cardiovasc Trans Res 2014;7:310-320.

54 Kong SS, Liu JJ, Hwang TC, Yu XJ, Zhao M, Zhao M, Yuan BX, Lu Y, Kang YM, Wang B, Zang WJ: Optimizing the parameters of vagus nerve stimulation by uniform design in rats with acute myocardial infarction. PLoS One 2012; 7: e42799. 